\title{
The Value of the Yangzhou Storytelling of Rogue Pi Wu
}

\begin{abstract}
LIU Liu
Nanjing Tech University, Nanjing, China

Equally divided into three is the beauty of moonlight scenes of the world two of them are undoubtedly in

Yangzhou pinghua 評話 (Yangzhou storytelling), as a genre of vernacular performing arts, appeared in Yangzhou in the late Ming 明 (1368-1644) and early Qing 清 (1616-1912) times. The Yangzhou pinghua repertoire of Pi Wu lazi 皮五辣子 (Rogue Pi Wu) initially created in Yangzhou around the Qianlong 乾隆 (1735-1796) era has been passed down to the present times and performed by Yang Mingkun 楊明坤 (1949- ). In this paper, the author will examine some historical aspects of Yangzhou city that is reflected in the narrative of Rogue Pi Wu recited by Yang Mingkun and the basics of the repertoire of Rogue Pi Wu by referring to the historical documents related to Yangzhou pinghua and the modern studies on the history of Yangzhou city, aiming to point out that Yang's repertoire of Rogue Pi Wu is of great research value to the study on Yangzhou storytelling. In addition, the origins and values of this thesis and the methodology adopted in conducting the present research are introduced.
\end{abstract} Yangzhou. ${ }^{1}$ —Xu Ning (fl. 813)

Keywords: Yangzhou storytelling, Pi Wu lazi, performing arts, historical and literary values

\section{Yangzhou: The Birth Place of Yangzhou Storytelling}

The Yangzhou pinghua repertoire of Rogue Pi Wu performed in the Yangzhou dialect by Yang Mingkun was initially created in the Qing Qianlong era, and the narrative of the story concerns the daily life experiences of the Yangzhou people in Qing times completely. Thus, the geographical features, the economic and cultural status of Yangzhou in the Qing dynasty, and even the linguistic features of the Yangzhou dialect are all reflected in the repertoire of Rogue Pi Wu performed by Yang Mingkun.

Yangzhou 揚州 has a history spanning more than 2,500 years, and has been a literary symbol of the site of dreams and illusions since the Tang 唐 dynasty (618-907). It is an inland prefecture-level city in the central part of modern Jiangsu 江蘇 Province, situated on the north bank of the Yangtze 揚子 River and southeast of the Huai River 淮河. Known in history as “Huai zuo ming du" 淮左名都 or “a famed city to the east of the Huai River", Yangzhou was renamed from Guangling 廣陵 during the Sui 隋 dynasty (581-618) to designate the area of present-day Yangzhou. Constructed as a military base in 486 BC, Yangzhou was initially called Hancheng 邗城 (Finnane, 2004, pp. 18-24; Wang, 2002, p. 3). The Hangou 干阝溝 Canal known as the first waterway in history to connect the Huai and Yangtze Rivers, was constructed in the same year as Hancheng, also primarily for military purposes. The Han Canal is the oldest extant part of the Grand Canal of China,

LIU Liu, Ph.D. candidate, Dr., lecturer, College of Overseas Education, Nanjing Tech University, Nanjing, China.

${ }^{1}$ All translations of Chinese terms and texts in this thesis, unless otherwise indicated, are my own. 
linking the Yellow River 黃河 and the Yangtze River (Wang, 2002, pp. 50-52).

The construction of Yangzhou in the early imperial period was mainly due to its position of strategic importance, and the city became a national centre of economy and culture in late medieval period and remained so for more than 1,000 years until the early 19th century. Indeed, Yangzhou is a most famous historical and cultural city in China. Its beauty and charm find full expression in "Seeing off Meng Hao-ran at Yellow-crane Tower on His Going to the Broad Mound [Yang-chou]", a heptasyllabic quatrain (qiyan jueju 七言絕句) written by the great Tang dynasty poet Li Bai 李白 (701-762). The poem reads (Dolby, 2006, pp.153-54):

\footnotetext{
My old friend farewell-West!- from Yellow-crane Tower;

But in mist-and-flower April down to Yang-chou heads!

His lone sail's far silhouette dies into the azure air,

And I only see the Yangtze flowing to horizon edge.
}

The city of Yangzhou features many lanes, rivers, and private gardens, as vividly described in Yang's version of Rogue Pi Wu. The crisscrossed lanes and streets that ramify throughout the city are one of the most characteristic features of Yangzhou. There are more than 600 lanes within a small area of no more than seven square kilometers (Huang, 2005, pp. 34-40). Some of the names of the lanes in Yangzhou are recorded in Rogue Pi Wu as recited by Yang Mingkun, such as Mingwa 明瓦 Lane, Yiren 一人 Lane (see Figure 1), and Baizi 百子 Lane (Yin, Jiang, \& Yang, 2015).

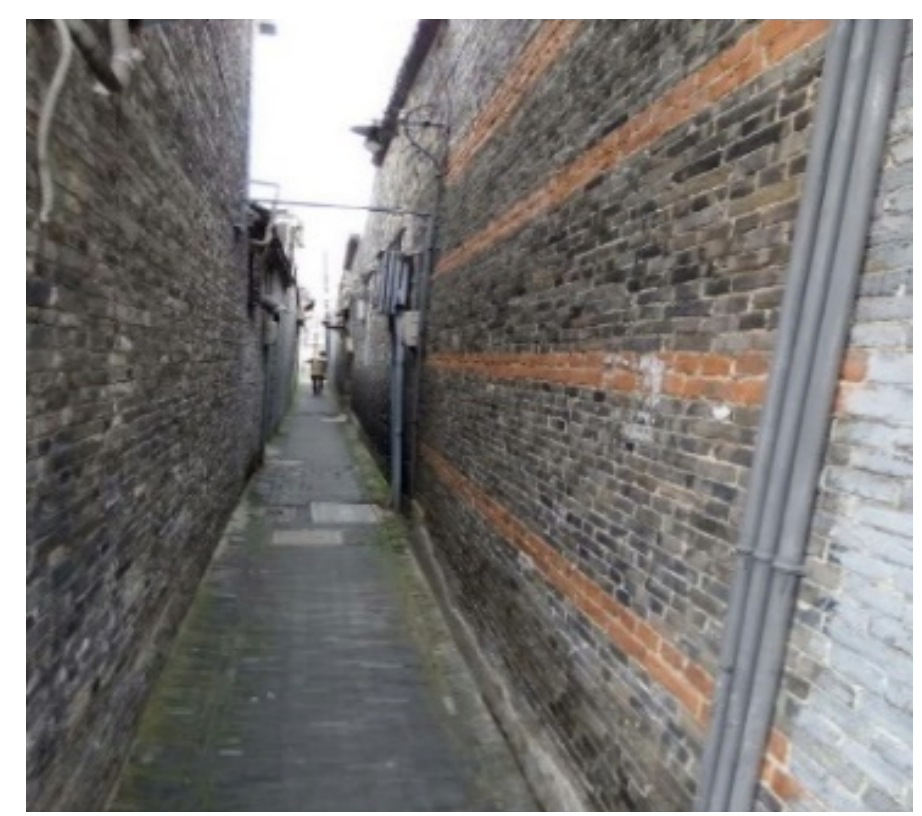

Figure 1. A narrow lane restricted to one person. Guoqing road, Yangzhou.

The Grand Canal, connecting North China and South China, significantly impacted the development of Yangzhou from the Sui to the Qing era. Over this long period, waterway transportation ascendancy, the salt industry and trade decided the economic position of Yangzhou in Imperial China. Yangzhou experienced two golden ages in history, one in the Tang and the other in the Qing era. During the Tang dynasty, Yangzhou was the greatest commercial centre and port of trade in the country and also became the centre of salt monopoly government in the late Tang era (Wu, 2013, pp. 2-3). This is reflected in the well-known folk saying, "Yangyi Yier" 揚一益二, which suggests that Yangzhou was the greatest commercial port with Yizhou 益州 (modern 
Chengdu 成都) coming second in the Tang era (Wei, 2000, pp. 232-233). Yangzhou is located at the centre of the Jiang-Huai 江淮 area between the Yangtze and Huai rivers and situated at the junction of the Grand Canal and the Yangtze River. When shuttling between the northern and southern cities by waterway or land, people needed to pass by Yangzhou. Thus, Yangzhou owed its prosperity to the growing volume of traffic between the north and the south. In the Tang times, "It became a hub of interregional and even foreign trade and was host to a large population of merchants from inner and western Asia” (Finnane, 2004, p. 22).

It was the waterway system within Yangzhou boundaries that made Yangzhou the centre of north-south trade and communication in late Imperial China, subsequently giving the Chinese people the incorrect impression that Yangzhou was located in the wealthiest area south of the Yangtze River under the Qing, which was traditionally known as Jiangnan 江南 (Chen \& Qing, 2005, pp. 113-120). In the story of Rogue Pi Wu recited by Yang Mingkun, when Pi Wu pretends to be a Guangdong merchant living in a luxurious ship to cheat others, no one questions his identity because it is common to meet wealthy merchants in Qing Yangzhou given the presence of the convenient waterway transportation. The description of the prosperous port is as follows (Yin et al. 2015, 620-621):

Xiao Xizi goes to the most massive port and sees various types and sizes of boats floating on the river. [...] He says to himself, "Here are cargo ships, manned vessels, garbage ships, but where is the mansion-on-water [shui gongguan] of the Guangdong merchant?"

The phrase "Mansion-on-water" implies that the boat is as luxurious and spacious as a mansion on land.

During the Qing dynasty, the salt monopoly provided the financial foundations for Yangzhou to become one of the most prosperous and wealthiest cities in China. According to the accounting details in the Yanye timing beiji 鹽業題名碑記 (Tablet Inscription with Author's Name about Salt Industry) by Li Fayuan 李發元 (ca.1684-ca.1769), more than half of the quota of the Empire's salt tax revenue was drawn from Yangzhou (Wu, 2013, p. 120). Furthermore, the Grand Canal conferred importance on Yangzhou, the main port of the only north-south waterway route, as the centre of interregional communication and trade, as well as significantly contributing to the re-emergence of Yangzhou as one of the principal commercial cities in late Imperial China (Hu \& Pan, 1993, p. 16). Liang-huai 兩淮 merchants had a stable and close relationship with the central government, and they were rich enough to be considered a private bank of the empire to fund natural disaster relief and infrastructure (Wei, 2000, pp. 61-64; Wang, 2002, pp. 39-40). ${ }^{2}$ The emperors' travels to Yangzhou led to garden buildings reaching a higher level, with the influence of distinguishing characteristics from the north. "With frequent tourism by Qing emperors Kangxi and Qianlong, the typical architectural features of the Imperial Palace were incorporated into Yangzhou garden construction, i.e. covered walkways, gazebos, standard pavilions" (Finnane, 2004, pp. 198-199; Zhu \& Wang, 2001, pp. 204-216).

We can only imagine how luxurious these private gardens must have been in the Qing dynasty, as some were even used as Imperial travel palaces. In the story Rogue Pi Wu told by Yang Mingkun, Pi Wu buys a luxurious garden house when he becomes rich. The narrative on the decoration in the garden house reads as follows (Yin et al. 2015, p. 664):

This is a garden house built in nine suites. He goes through the first and second to the third. He is shocked when

\footnotetext{
${ }^{2}$ The large area on both sides of the Huai River directly to the north of the Yangtze River is called Liang-Huai. Yangzhou is one of the important cities of the Liang-Huai area. Most of the Qing Liang-Huai merchants are not locals of Yangzhou but come from Shaanxi, Shanxi, Anhui, Zhejiang, Jiangxi 江西, Hubei 湖北, and other cities of Jiangsu.
} 
seeing lots of chairs and long desks made of precious wood, antiques and paintings. There are lots of porcelain, jade articles, carved wooden furniture and bronze wares in the third hall. Pi Wu looks around and says to himself, "Oh my god! The chairs and long desks, antiques and paintings here, any one of them is worth around twenty thousand taels silver." [...] The fourth and fifth halls are decorated in the same style.

Above is a description of a private garden house in Qing Yangzhou: It includes valuable antiques and paintings in the hall, chairs and desks made of precious wood, and exquisite halls and rooms built in the garden (see Figures 2 and 3). Nearly all the owners of the private gardens were salt merchants. Qing Yangzhou experienced its second golden period when salt merchants from Shanxi 山西, Shaanxi 陝西, Anhui 安徽, Jiangxi 江西, and Zhejiang 浙江 came to Yangzhou to conduct business. The wealth brought to Yangzhou by these merchants provided an excellent opportunity for garden builders to exchange their experiences and put their design skills into practice, significantly contributing to the now renowned Yangzhou garden arts. In addition, wealthy merchants were interested in decorating their gardens with valuable antiques and paintings to exhibit their wealth. Hence, it is not surprising to find expensive furniture in Pi Wu's house.

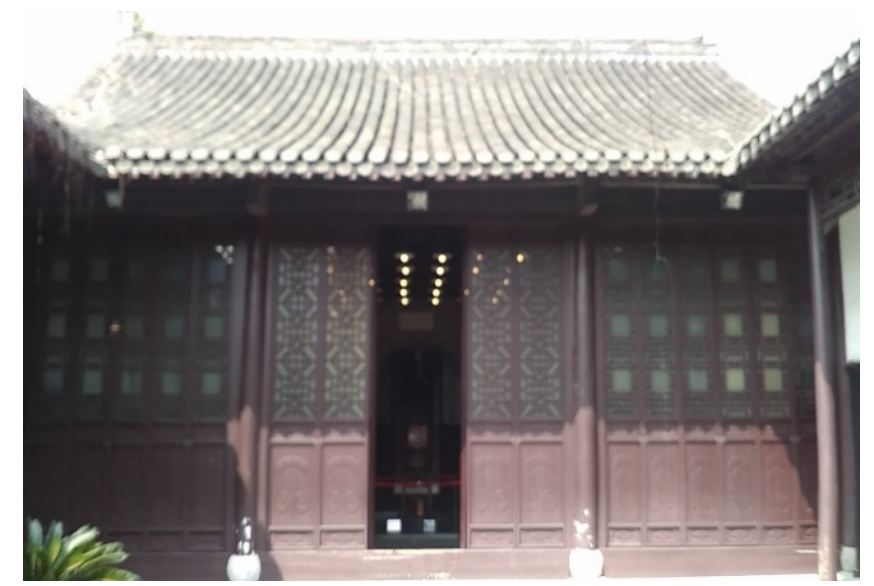

Figure 2. A wood hall built in the private garden in Qing times. Dongguan 東關 Street, Yangzhou.

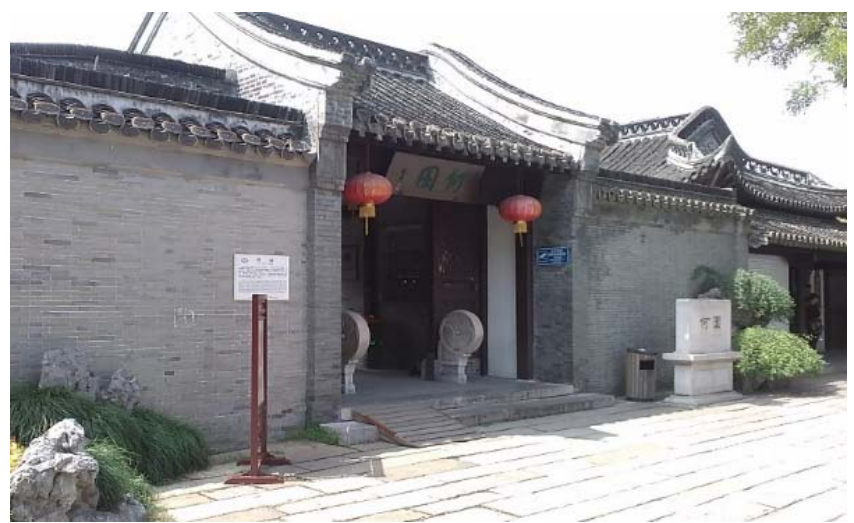

Figure 3. Outside of the private garden built in Qing times. Xuningmen 徐凝門 Street, Yangzhou.

During the Qing dynasty, the commercial activities of sojourning merchants strengthened the position of Yangzhou as a significant economic and cultural centre in the empire and also made Yangzhou the capital of luxury and consumption in China (Ke, 2006, pp. 278-293; Sun, 2005, pp. 14-20; Wu, Zhao, \& Wang, 2005, pp. 38-45). Merchants from near and afar came to Yangzhou to earn money. This is vividly described in the story of Pi Wu is as follows (Yin et al., 2015, pp. 629, 248, 511): 
Yao Er, the boss of the fur shop, is from Shanxi; Wang Youcai from Nanjing is the owner of Fusheng Yuan teahouse; Great-grandfather Wan Er, the owner of the pawn shop is from Zhenjiang.

However, very few ordinary Yangzhou residents were engaged in commercial activities with the sojourning merchants for profit (Finnane, 2004, pp. 6-9). In contrast to the wealthy provincial merchants, ordinary Yangzhou locals preferred to live a practical and low-profile life. The ordinary houses of Qing Yangzhou were simple, built according to the shape of the streets and lanes, adopting the concept of "Take things as they are". Most ordinary houses, with little exception, were built with a tianjing 天井 (courtyard) in it for lighting, ventilation, and drainage. Sometimes, a courtyard also functioned as a drawing room. In Yang's narrative of Rogue Pi Wu, Wang Youcai, the owner of Fusheng Yuan teahouse, turns the courtyard attached to his house into a drawing room to accommodate more people. The description is: "Go through the hall, a small courtyard is found. In the yard, there are four big water vats. [...] Now, many people are sitting on the vat covers" (Yin et al, 2015, p. 248).

The development of the Yangzhou dialect has a close connection with several waves of the southward migration in history, suggested by the linguistic evidence from the text of Rogue Pi Wu performed by Yang Mingkun. The Yangzhou dialect developed from the interaction between the northern and southern dialects, in particular, $\mathrm{Wu}$ dialects, in the Sui and early Tang periods, and its growth has always been accompanied by such an interaction (Zhang, 2000, pp. 228-229). Following the collapse of the Ming dynasty, the Manchu Qing General Duoduo 多鐸 (1614-1649) ordered a ten-day massacre, killing almost eighty to ninety per cent of Yangzhou residents (Huang, 2005, p. 135; Wang, 2002, p. 34.). After this slaughter, large numbers of immigrants from the north and south of China came to Yangzhou. This was not the first large-scale migration to Yangzhou; several periods of southward migration to the Jiang-Huai area, including Yangzhou, had taken place since the late Western Jin 西晉 dynasty (AD 266-316). For example, a repopulation policy was issued and applied in the Jiang-Huai area during the Southern Song 南宋 dynasty (1127-1279) to obtain resources to strengthen defences (Zhou, 2007, pp. 130-133; Coblin, 2002, p. 533). The several waves of migration that took place from the Western Jin onwards greatly influenced the development of the Yangzhou dialect; linguistic evidence of this abounds in Rogue Pi Wu by Yang Mingkun (see 5.3).

The modern Yangzhou dialect is one sub-dialect grouping of Jiang-Huai Mandarin (Zhang, 2002, pp. 5-7; Yan, 2006, pp. 1-3, 60-86). ${ }^{3}$ The foundation of the Jiang-Huai Mandarin group known today was laid firmly by immigrants principally from the north in the late Northern Song 北宋 (960-1127) and early Southern Song dynasties (Coblin, 2002, p. 534.). The phonological system of the Yangzhou dialect follows that of the Mandarin dialect or the Northern dialect group, while retaining some phonetic features of the Southern dialects, such as wenbai yidu 文白異讀 (literary and colloquial reading) and rusheng 入声 Middle Chinese (MC) entering tone. ${ }^{4}$ It also presents unique features such as podu 破讀 reading (Wang, 1986, pp.

\footnotetext{
3 There are seven major dialects within the Chinese language family: Mandarin, $\mathrm{Wu}$ 吳, Cantonese 廣東, Gan 贑, Hakka 客家, Min 閩, and Xiang 湘. The Mandarin dialect has four sub-dialect groups: Northern Mandarin 北方官話, Southwestern Mandarin 西南官話, Northwestern Mandarin 西北官話, and Jiang-Huai 江淮 or Lower Yangtze Mandarin 下江官話.

${ }^{4}$ In modern Chinese dialects, a syllable can have two different phonetic realisations: colloquial pronunciation, derived from the realisation of daily talking, and literary pronunciation, derived from the realisation of literary reading. Literary and colloquial pronunciations commonly exist in Southern dialects, especially in the Min and Wu dialect groups. At the present time, the Yangzhou dialect belongs to the Northern dialect group; however, it retains more than 50 syllables containing literary and colloquial pronunciations. Entering tone is one of the four syllable types in the phonology in Middle Chinese. Although translated as "tone," an entering tone is not a tone in the phonetic sense but a syllable that ends in a stop consonant or a glottal stop.
} 
108-111). ${ }^{5}$ These linguistic characteristics have won Yangzhou dialect a reputation of bu nan bu bei, yi nan yi bei 不南不北, 亦南亦北 (not south not north, but also south and north), which finds full expression in.

The repertoire of Rogue Pi Wu performed by Yang Mingkun. Its value to scholars of historical linguistics and dialectology can never be overestimated. The narrative of Rogue Pi Wu performed by Yang also reflects the social context of Yangzhou in the Qing dynasty, providing a fascinating window into the daily life of the ordinary people of Qing Yangzhou.

\section{The Basis of the Yangzhou Storytelling of Rogue Pi Wu}

Yangzhou pinghua, as represented by the repertoire of Rogue Pi Wu performed by Yang Mingkun, is a typically genre of traditional Chinese performing arts.

Among the genres of Yangzhou narrative arts performance, Yangzhou storytelling is the most influential. It enjoyed popularity in Qing Yangzhou and is still performed in modern Yangzhou. It is a genre of Chinese chantafables on the list of "China's intangible cultural heritage". ${ }^{6}$ It refers to the professional performance of telling stories in prose without musical accompaniment, predominantly in the Yangzhou dialect. In the shuchang 書塲 (story house) or chaguan 茶舘 (teahouse), the performer, attired in traditional costumes, tells a story while sitting behind a small square desk with a xingmu 醒木 (talking stopper) on it and holding a zheshan 摺扇 (folding fan) (see Figure 4). ${ }^{7}$ This is the setting of a typical Yangzhou storytelling performance.

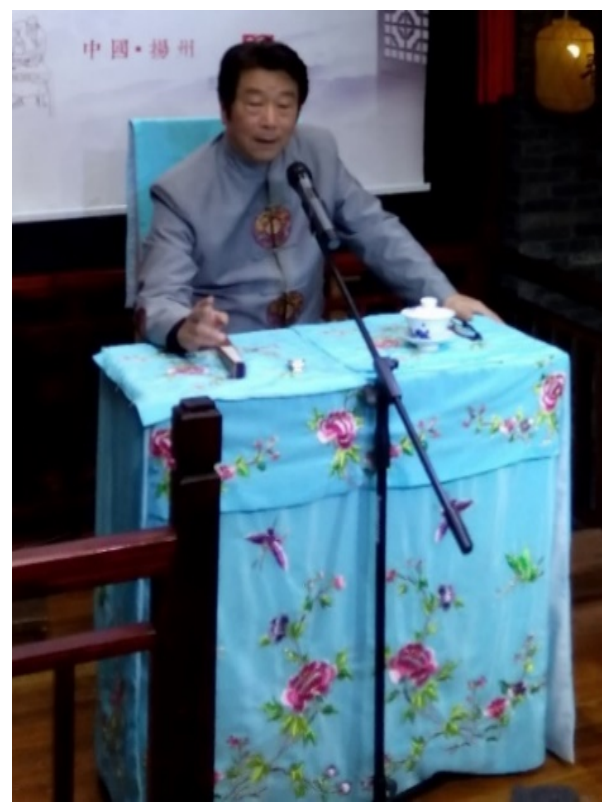

Figure 4. Yang Mingkun performs Yangzhou storytelling. Pi Wu shuchang 皮五書場 ( $\mathrm{Pi}$ Wu Story House), Dongguan Street, Yangzhou.

The history of Yangzhou storytelling can be traced back to the Song 宋 dynasty (960-1279). Hu Shiying 胡士瑩 (1901-1979) states that (Hu 1980, p. 614):

\footnotetext{
${ }^{5}$ Podu refers to the situation in which the tone, final or initial of a morpheme is changed when distinguishing different but related lexical or syntactic meanings of a morpheme, or two morphemes that share a phonetic realisation. Usually, podu phonetic realisation follows the phonological system of the modern Northern dialects group, and the original realisation retains the phonetic tradition of the Middle Chinese dictionary.

${ }^{6}$ No. 238 V-2 in the list of "China's intangible cultural heritage" is the Yangzhou pinghua.

7 All photos presented in the thesis are taken by the author.
} 
Pinghua, following the traditions of the performance of jiangshi 講史 (historical tale-telling) from the Song and Yuan dynasties, was very well developed in the Qing dynasty. Initially, the city of Yangzhou was the centre of pinghua performing arts, after which many other cities developed their own vernacular storytelling. However, the centre of pinghua performing arts is still in Yangzhou.

It appears that the jiangshi of the Song dynasty was the fountainhead of Yangzhou storytelling (Lu, 1982, pp. 134-135; Meng \& Ning, 2003, pp. 165-178; Wang, 2006, pp. 46-50; Xiao \& Liu, 2003, pp. 126-45, 411-19). Liu Jingting 柳敬亭 (1587-1670), Kong Yunxiao 孔雲霄 (fl. ca.1650), and Han Guihu 韓圭湖 (fl. ca.1600) are named as master Yangzhou pinghua storytellers by Li Dou 李鬥 (1749-1817) in the Yangzhou huafang lu 揚州畫舫錄 (Reminiscences from the Pleasure Boats of Yangzhou) (Li, 1797/1997, p. 257).

The repertoires of Yangzhou storytelling are mostly adapted from Ming and Qing zhanghui xiaoshuo 章 回小說 (chapter-division novels). Yangzhou storytellers recreate stories of their own by incorporating and adapting splendid plots of these novels (Chen, 1985, pp. 108-112). The most noteworthy of these are the Shuihu zhuan 水澈傳 (The Water Margin), the Sanguo yanyi 三國演義 (The Romance of the Three Kingdoms), and the Xiyou ji 西遊記 (The Pilgrimage to the West). Today, we often hear of Wang Shaotang 王少堂 (1899-1968) as a master storyteller. His Shuihu repertoire has been revered as the Wang School of The Water Margin.

Only a few Yangzhou pinghua repertoires performed in Qing times were newly created independently from the chapter-division novels. Of the 10 storytelling performances mentioned by Li Dou in his Yangzhou huafang lu, only three are new creations. These are the Qingfeng Zha 清風閘 (Pure-Wind Dyke), the Feituo zhuan 飛駬傳 (Legend of Flying Hunchback), and the Yangzhou hua 揚州話 (Story of Yangzhou Dialect) (Li, 1797/1997, p. 258). In his A Brief History of Chinese Fiction, Lu Xun, father of modern Chinese literati, explains the reason for the appearance of several newly created repertoires in Qing times. He says: "Men's tastes change with the times, and as readers grew tired of old books, new trends developed" (Lu, 1982, p. 336). This also explains the reason for the emergence of the newly created repertoires of Yangzhou storytelling in Qing times, namely The Legend of Feituo, The Story of Yangzhou Dialect, and Pure-Wind Dyke, the last of which has also been referred to as Pi Wu lazi or Rogue Pi Wu since 1985.

The Legend of Feituo and the Story of Yangzhou Dialect fail to survive, and still extant is Rogue Pi Wu that represents the repertoire created in Qing times. One of the masterly Yangzhou storytelling repertoires from the Qing dynasty performed in modern Yangzhou is Rogue $\mathrm{Pi} W u$, also known as the "Pu men $\mathrm{Pi} W u$ " 蒲門皮 五 ( $\mathrm{Pu}$ School of $\mathrm{Pi} \mathrm{Wu}$ ). The present storyteller of the repertoire is Yang Mingkun, the ninth-generation inheritor of the $\mathrm{Pu}$ School. He is a national first-class actor and a member of the Chinese Artists Association. In 1990, he was recognised as one of the "10 National Master Storytellers" together with nine other artists, including Jiangkun 姜昆 (1950-), Liu Lanfang 劉蘭芳 (1944-), and Tian Lianyuan 田連元 (1941- ).

Pure-Wind Dyke can be read as an autobiography of the author; it also records scenes of Qing-era Yangzhou. According to the story performed by Yang Mingkun, Pure-Wind Dyke is set in the Song dynasty (Yin et al., 2015, p. 203), although it was initially created in Yangzhou by Pu Lin 蒲琳 (fl.1780) who lived during the reign of Qianlong. Also known as Pu Tianyu 蒲天玉, Pu Lin was the author and first performer of Pure-Wind Dyke. Pi Wu 皮五 is the nickname of the protagonist Pi Fengshan 皮鳳山 in Pure-Wind Dyke. ${ }^{8}$ It

\footnotetext{
${ }^{8}$ The full name of the protagonist is Pi Fengshan 皮奉山 in all versions of the text, but Hu Shiying wrote it in the form of 皮奉 三 in Huaben xiaoshuo gailun. 山 and 三 share identical phonetic realisation in the Yangzhou dialect.
} 
is derived from the fanqie 反切 of the author's surname Pu 蒲 (Fuller, 2004, pp. 83-84). ${ }^{9}$ As Li Dou states in the Yangzhou huafang lu (Li, 1797/1997, p. 205):

Yangzhou storytelling is not difficult to perform, but the whole existing repertoire is very familiar to people. So, Pu wrote a story called Pure-Wind Dyke, based on his life experiences, about a character named Pi Wu.

As shown above, the story of Pure-Wind Dyke is based on Pu Lin's life experiences in Yangzhou during the Qing dynasty. Thus, what is said in it about the geography and culture of Yangzhou is not those of Song Yangzhou city, but of Qing Yangzhou. Fortunately, the narrative concerning Qing Yangzhou city has been well-preserved and handed down to the present storyteller Yang Mingkun. Yang Mingkun stated in an interview, "I think, as a pinghua storyteller, I should take the responsibility of propagating our Yangzhou traditional culture. Differing from other Yangzhou pinghua repertoires, the repertoire of Pi Wu was born in Yangzhou and deeply rooted in the traditional culture of Yangzhou. I should preserve it well in my generation and transmit it to my apprentice". 10

The Yangzhou storytelling of Pure-Wind Dyke/Rogue Pi Wu also exists in written forms, some of which are performance-style texts (Berezkin, 2010, p. 34). ${ }^{11}$ The author will use three versions of these performance-style texts as primary source material for this thesis (see Figure 5) (Wang, Liu, \& Sun, 1996; Wang, Chen, \& Li, 1985; Yin et al., 2015). All of the storytellers of Pure-Wind Dyke/Rogue Pi Wu have their own unique features and distinctive aspects to their performance, but the only storyteller to have had their performances recorded in books or on video are Pu Lin, Yu Youchun 余又春 (1919-1995), and Yang Mingkun. The Fengxiaoxuan 奉孝軒 edition of Pure-Wind Dyke was published by Meixi zhuren 梅溪主人 (Master of Plum Spring) (ca.1711-1799) in the 24th year of Jiaqing 嘉慶 (1796-1820) of the Qing dynasty. The publisher was not familiar with Pu Lin's repertoire and the motives for publication were merely profit based. As a result, the Fengxiaoxuan edition of Pure-Wind Dyke is different from Pu Lin's repertoire in many ways, ranging from storyline to theme (Dong, 2008, pp. 106-107; Wang et al., 1996, p. 2). The Huaxuanzhai 華軒斎 edition of Pure-Wind Dyke, which was published in the first year of Daoguang 道光 (1821-1850), was based on Pu Lin's repertoire and reprinted in the thirteenth year of Tongzhi 同治 (1861-1875). Based on the repertoire of Yu Youchun, two books were published in 1985, titled Rogue Pi Wu and Pure-Wind Dyke, respectively. In 1996, the Huaxuanzhai edition of Pure-Wind Dyke was reprinted (Wang et al., 1996, p. 5). The year 2015 witnessed the publication of a text and video of Rogue Pi Wu based on the repertoire of Yang Mingkun. Yang Mingkun's oral performance of the Pi Wu lazi was transferred to video in 2015. ${ }^{12}$

\footnotetext{
${ }^{9}$ Fanqie is a style of notation used by Chinese scholars since the end of the Han 漢 dynasty (206 BC-AD 220) to indicate the pronunciation of a word. In a fanqie, one takes the initial of the first word and the final of the second word: the two pieces added together give the pronunciation of the word being glossed. See Fuller, 2004, pp. 83-84. For example, we can use the initial of Pí 皮 (Chinese surname; skin) and the final, the tone of wǔ 五 (five) to indicate the pronunciation of pǔ 蒲 (Chinese surname).

${ }^{10}$ Interview with Yang Mingkun, 18 April 2016.

${ }^{11}$ According to Berezkin, the term "performance-style text" was suggested by Anne E. McLaren to describe the texts of the 15th century, or cihua 詞話 (stories with passages in verse), discovered in the Xuan family tomb in Jiading county near Shanghai in 1967. Berezkin applied this in the dissertation to designate the texts that reveal features of the traditional oral literature but have reached us only in written form. In the present research, I apply it to refer to the text transcribed from the Yangzhou pinghua repertoire of the Qingfeng Zha performed by Pu Lin and the Pi Wu lazi by Yu Youchun and Yang Mingkun.

${ }^{12}$ Pi Wu lazi (oral performance by Yang Mingkun), Jiangsu Fenghuang dianzi yinxiang chuban she 江蘇鳳凰電子音像出版社 (Jiangsu Phoenix Electronic Audio and Video Publishing House, 2015). The complete video set consists of 50 discs.
} 

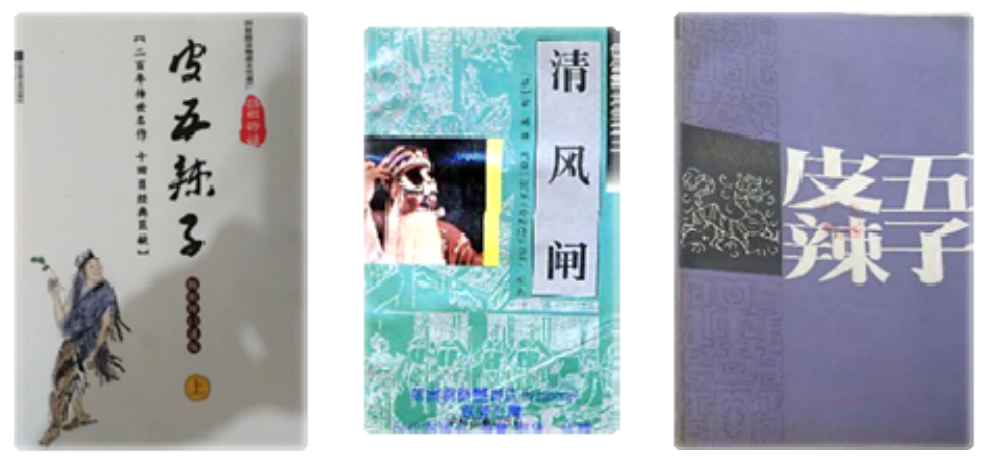

Figure 5. Three versions of performance-style transcribed texts published in 2015, 1996, and 1985, respectively (from left to right).

Like other genres of Chinese chantafables, Yangzhou pinghua has a strong affinity with the historical tale-telling in the Song dynasty and still is performed in Yangzhou today. Differing from most of the Yangzhou pinghua repertoires from the Qing dynasty which are adapted from the well-known traditional chapter-division novels, the repertoire of Rogue Pi Wu was newly created in Qing times and has been successfully transmitted to present times. The Huaxuanzhai edition of Qingfeng Zha reprinted in 1996, the Pi Wu lazi published in 1985, and the Pi Wu lazi published in 2015 are the three texts transcribed from the repertoires of Pi Wu by Pu Lin, Yu Youchun, and Yang Mingkun, respectively.

\section{Conclusion}

As mentioned above, the repertoire of Rogue $\mathrm{Pi} W u$ is of great value to the historical inquiries into the fields of performance literature and dialectology. Also, Yang's repertoire of Rogue Pi Wu offers itself as a good case for the study on the current status of Yangzhou pinghua.

\section{References}

Berezkin, R. (2010). The development of the Mulian story in Baojuan texts (14th-19th centuries) in connection with the evolution of the genre (Ph.D. dissertation, University of Pennsylvania).

Chen, W. L. (1985). Cong changpian xiaoshuo fazhan dao changpian pinghua (The development of full-length novel to full-length pinghua storytelling). Journal of Yangzhou Normal University, 1, 108-112.

Chen, X. M., \& Qing, Y. (2005). Yangzhou mingshui (Well-known rivers in Yangzhou). Yangzhou: Guangling Publishing House.

Coblin, W. S. (2002). Migration history and dialect development in the lower Yangtze watershed. Bulletin of the School of Oriental and African Studies, 3, 533.

Dolby, W. (2006). Three hundred Tang dynasty poems (trans. with commentaries and annotations). Edinburgh: Carreg Publishers.

Dong, G. Y. (2008). Lun Qingfeng Zha de yanbian he yiyi (Discussion of the significance of evolution of Pure-Wind Dyke). Heilongjiang Social Sciences, 106, 106-107.

Finnane, A. (2004). Speaking of Yangzhou: A Chinese city, 1550-1850. USA: Harvard University Press.

Fuller, M. A. (2004). An introduction to literary Chinese. Cambridge, MA: Harvard University Asia Centre.

Hu, M., \& Pan, B. M. (Eds.). (1993). Yangzhou Wenhua gaiguan (Outline of Yangzhou culture). Nanjing: Nanjing Publisher.

Hu, S. Y. (1980). Huaben xiaoshuo gailun (General introduction to Huben fiction). Beijing: Zhonghua Book Company.

Huang, J. L. (2005). Yangzhou mingxiang (Well-known lanes in Yangzhou City). Yangzhou: Guangling Publishing House.

Ke, L. (2006). Minsu shiye zhong de Qingdai Yangzhou su wenxue (Look at the folklore of Qing Yangzhou from a folk-custom view). Shanghai: Shanghai Academy of Social Sciences Publisher.

Li, D. (1797/1997). Yangzhou huafang lu (Reminiscences from the pleasure boats of Yangzhou). Beijing: Zhonghua Book Company.

Lu, X. (1982). A brief history of Chinese fiction. Beijing: Foreign Language Press. 
Meng, Z. L., \& Ning, Z. Y. (2003). Zhongguo xiaoshuo yishushi (History of the art of traditional Chinese fiction). Zhejiang: Ancient Books Publisher.

Sun, C. Y. (Eds.). (2005). Yangzhou mingyuan (Well-known gardens in Yangzhou). Yangzhou: Guangling Publishing House.

Wang, C., Chen, W. L., \& Li, Z. (Eds.). (1985). Pi Wu lazi (Rogue Pi Wu) (Transcribed from Yu Youchun's repertoire). Nanjing: Jiangsu Literature and Art Publishing House.

Wang, H. (2002). Yangzhou sanji (Random notes on Yangzhou). Nanjing: Jiangsu Ancient Books.

Wang, Q. H. (2006). Huaben xiaoshuo wenti yanjiu (Stylistic study of Huaben fiction). Shanghai: Huadong Normal University Publisher.

Wang, S. H. (1986). Yangzhou kouyu zhong de podu (Podu realisations in oral Yangzhou dialect). Journal of Social Sciences of Yangzhou Normal University, 1, 108-111.

Wang, Y. Z., Liu, C. Y., \& Sun, S. L. (Eds.). (1996). Qingfeng Zha (Pure-wind dyke) (Transcribed from Pu Lin's repertoire). Zhengzhou: Zhongzhou Ancient Books Publishing House.

Wei, M. H. (2000). Eeshisi qiao mingyue ye, Yangzhou (The twenty-fourth bridge at the night with a bright moon, Yangzhou). Shanghai: Shanghai Ancient Books Publisher.

Wu, H. B. (2013). Qingdai Liang-huai yanye zhongyaoxing zhi dingliang fenxi (The quantitative analysis of the importance of the salt industry of the Liang-huai area under the Qing dynasty). Journal of Sichuan University of Science and Technology (Social Science Edition), 2, 2-3.

Wu, J. K., Zhao, L. C., \& Wang, Z. T. (Eds.). (2005). Yangzhou Mingzhai (Well-known mansions in Yangzhou). Yangzhou: Guangling Publishing House.

Xiao, X. Q., \& Liu, F. Y. (2003). Huaben xiaoshuo shi (History of the Huaben fiction). Zhejiang: Ancient Books Publisher.

Yan, M. M. (2006). Introduction to Chinese dialectology. Muenchen: Lincom GmbH.

Yin, B. D., Jiang, Y. L., \& Yang, W. H. (Eds.). (2015). Pi Wu lazi (Rogue Pi Wu) (transcribed from Yang Mingkun's repertoire). Nanjing: Jiangsu Phoenix Literature and Art Publishing House.

Zhang, B. (2002). Xinbian xiandai Hanyu (New edition of modern Chinese language). Shanghai: Fudan University Press.

Zhang, M. (2000). Syntactic change in southeastern mandarin: How does geographical distribution reveal a history of diffusion? In B. X. Ding and A. Q. Yu (Eds.), In memory of Professor Li Fang-Kuei: Essays on linguistic change and the Chinese dialects (pp. 228-229). USA: University of Washington.

Zhou, Y. Z. (2007). Nan Song shiqi de huaiyang yimin (Migration of Huai-Yang area in the Southern Song dynasty). Xungen, 1, 130-133.

Zhu, Z. H., \& Wang, Y. (2001). Yanshang yu Yangzhou (The salt merchants and Yangzhou). Nanjing: Jiangsu Ancient Books Publisher. 